University of New Haven

University of

New Haven

Digital Commons@ New Haven

Civil Engineering Faculty Publications

Civil Engineering

2015

\title{
Reflections on Interdisciplinary Sustainability Research with Undergraduate Students
}

Can B. Aktas

University of New Haven, caktas@newhaven.edu

Follow this and additional works at: http:// digitalcommons.newhaven.edu/civilengineering-facpubs

Part of the Civil Engineering Commons, Engineering Education Commons, and the Higher Education Commons

\section{Publisher Citation}

Aktas, C.B. (2015) 'Reflections on interdisciplinary sustainability research with undergraduate students', International Journal of Sustainability in Higher Education, 16(3), pp. 354-366. doi: 10.1108/ijshe-11-2013-0153.

\section{Comments}

This is the author's accepted version of the article published in International Journal of Sustainability in Higher Education. The version of record can be found at http://dx.doi.org/10.1108/ijshe-11-2013-0153. 


\title{
Reflections on Interdisciplinary Sustainability Research with Undergraduate Students
}

\author{
Can B. Aktaş, Ph.D. \\ Department of Mechanical, Civil, and Environmental Engineering, University of New Haven, \\ West Haven, CT, USA. E-mail: caktas@newhaven.edu
}

Paper submitted: 25 November 2013

Paper revised: 18 March 2014

\begin{abstract}
Purpose - The intent of the article was to convey experiences with pioneering interdisciplinary sustainability research by involving undergraduate students. Experiences with initiating and conducting multiple research projects spanning engineering and sustainability are described, and recommendations for programs and faculty in other institutions of higher education that plan to implement or support similar endeavors are discussed.

Approach - The article and presented conclusions are based on three separate research projects, where specific examples as to how those projects were developed as well as challenges and rewards faced during the project are described.

Findings - It is concluded that faculty should not refrain from working with students from different backgrounds and disciplines. Bringing different backgrounds and perspectives to a project enables a big picture view of problems at hand and leads to better solutions that are more in line with the three pillars of sustainability, while at the same time providing valuable hands-on experience to undergraduate students.

Originality/value - By its very definition, sustainability is an interdisciplinary field and thus requires novel approaches for education and research compared to other settled fields of science. A viable way to increase the role of sustainability in higher education is to foster interdisciplinary research and teaching. The institutions role in promoting such efforts have been discussed together with example strategies that were found to be successful as well as those who were not. The article presents results of potential successes in projects where the traditional disciplinary bounds have been breached, and an interdisciplinary approach has been used to achieve project goals. The article also gives examples on what types of sustainability research can be conducted with undergraduate students.
\end{abstract}

Keywords Multidisciplinary; Interdisciplinary; Hands-on learning; Higher education; Experiential; Sustainability; Sustainability education; Sustainable development

Paper type Research paper

\section{Introduction}

Institutions of higher education are undergoing rapid change due to the need to satisfy the demands of a new generation of incoming students and cater to their needs, while at the same time trying to respond to the growing concerns over global sustainability issues. 
Institutions that fail to quickly adapt to changing environments and new market forces often find themselves at a disadvantage, and institutions of higher education are no exception.

Many higher education institutions have included sustainability as part of their goals and mission statements in order to help create a better society (Rowe, 2007). However, change is difficult, and change at the curricular level towards sustainability, or in research is not a simple undertaking where few have truly succeeded (de la Harpe and Thomas, 2009). Higher education has come to be characterized with a traditional silo approach for both education and research. Experiences and reflections with pioneering interdisciplinary sustainability research that goes contrary to traditionally set boundaries in engineering are presented in the article. Sustainability education and research differs significantly compared to traditionally established disciplines in terms of content, and requires new approaches (Kates et al., 2001; Cortese, 2003; Brundiers et al., 2010).

The intent of the article was to convey experiences and reflections in initiating and conducting interdisciplinary research on sustainability with undergraduate students by giving specific examples from three separate research projects, and to present recommendations for programs and faculty in other institutions of higher education that plan to implement or support similar endeavors. While benefits and barriers to interdisciplinary research has been known on a conceptual level, case studies in literature related to engineering are scarce as engineering still remains to be mostly traditional in its methods of instruction and research approach (Borrego, 2010). Therefore, the presented study is a novel contribution to that end.

\section{Background}

Higher education institutions play an important but peculiar role towards progress and further development. While universities have historically been agents of societal change, they have nonetheless preserved themselves and remained attached to their traditions throughout the years (Stephens and Graham, 2010; Lozano et al., 2013). Even today, most higher education institutions focus on producing mono-disciplinary graduates even though students would be immersed in an interdisciplinary professional environment upon their graduation, as technical problems professionals face today are no longer limited to within traditional disciplinary boundaries (Elton, 2003; Lozano, 2010). The situation in academic research is not very different as traditional disciplines are still granted higher scientific recognition even though the need for interdisciplinarity is acknowledged by most (Oksen et al., 2009). Rafols et al. (2012) discuss how journal rankings exhibit a systemic bias in favor of mono-disciplinary research, and therefore the potential for researchers to comply with the traditionally set disciplines rather than explore interdisciplinary research potentials. Sustainability, with its goal to address environmental, economic, and societal problems is a good example to the interconnectedness of systems, and demonstrates how truly sustainable solutions can only be found by crossing over existing boundaries set forth by traditional disciplines (Uiterkamp and Vlek, 2007).

The United Nations has declared 2005 to 2014 the Decade of Education for Sustainable Development. Nearing the end of the decade, and after more than 20 years since the Rio 
Summit, it is debatable how much progress has been made towards incorporating sustainability into higher education. While there are efforts at various levels to promote sustainability in higher education, the pace at which the three pillars of sustainability environment, economy, and society - have been integrated across traditional disciplinary boundaries has not been sufficient to create a fundamental global change (Arbuthnott, 2009; Stewart, 2010; Hopkins, 2012; Tilbury, 2012).

Professional associations that have the role of certification or accreditation have also aimed at incorporating sustainability as part of their profession or accreditation requirement; partly to address the interdisciplinary professional environment graduates will be exposed to upon graduation, and partly to address growing sustainability problems of our times. $\mathrm{ABET}$, which is an internationally recognized governing body in assuring quality and stimulating innovation in applied science, computing, engineering, and engineering technology education, is one example institution that acknowledged the need to integrate sustainability into engineering programs (Jarvie, 2009). ABET have required that all undergraduate engineering programs prepare graduates to design systems, components, or processes to meet a multitude of realistic restraints, including sustainability needs. The requirement has been formally introduced under General Criterion 3 - Student Outcomes (ABET, 2014). American Society of Civil Engineers is an example for a professional certification association who has infused the goals of sustainability within their code of ethics. Fundamental Canon \# 1 requires civil engineers to comply with the principles of sustainable development in the performance of their professional duties (ASCE, 2014). Engineering is by no means the only field that underwent such changes but is a critical component to bring technical solutions to global sustainability problems.

From the curriculum side, the number of higher education institutions that have incorporated sustainability into their curricula has risen in the last decade (Lozano, 2010), and there are others that are exploring means to integrate sustainability into their curricula (Rusinko, 2010). Recent reports from the United States indicate that the number of interdisciplinary environmental and sustainability degree programs have increased by $57 \%$ between $2008-2012$, and that $21 \%$ of four year institutions offered sustainability academic programs in 2012 (Vincent et al., 2013a; Vincent et al., 2013b). Another relevant study by Clark et al. (2011) report that more than 1000 environmental sciences/studies programs exist in higher educational institutions in U.S. and Canada, but that there are also significant problems within the environmental program movement that can be tied to fragmentation, a lack of unifying and clearly defined goals, faculty with disciplinary expertise teaching interdisciplinary courses, and weaknesses in rational curricula development and educational philosophies employed.

From the research side, there has been an increasing interest towards the field of sustainability science as indicated by the exponential increase in the number of articles published within a 20 year timeframe between 1991-2011 (Nučič, 2012). Foundations such as the U.S. National Science Foundation (NSF) have supported interdisciplinary research as well, as indicated in the 2006-2011 and the more recent 2014-2018 Strategic Plan (NSF, 2006, NSF, 2014). 


\section{Institutional Support for Experiential Learning and Interdisciplinary Research}

Our institution of higher education is a strong proponent of experiential learning and interdisciplinary studies. Both approaches have been outlined in the institutional Strategic Plan for 2020. Experiential learning is a powerful tool to engage students and to enhance their learning. Engineering and as well as other applied sciences are prime candidates for application of experiential learning. However, when combined with interdisciplinary research, effective experiential learning for students need to be carefully designed and managed. Ryser et al. (2009) propose multiple factors for such interdisciplinary research that influence project outcomes and success including: previous experiences of students, student-faculty relationships, project finances, language, gender, and student ethnicity. The effect of these proposed factors on interdisciplinary research outcomes are evaluated in the discussions section of the article.

From the academic side, our institution has had several initiatives towards promoting environmental awareness, and increasing sustainability teaching and research on campus. A stand alone, interdisciplinary Sustainability Studies degree program was initiated in 2010, whose coordinator is the author on this article. True to the definition of sustainability, the degree program required students to take an equal number of courses from the Colleges of Engineering, Business, and Arts and Science. Having such a program with a visible coordinator acts as an attraction point for students from other programs who wish to take part in related activities or conduct sustainability research.

There were other attempts at promoting interdisciplinary research on campus. One such attempt was that in order to foster interdisciplinary research specifically among faculty, several Interdisciplinary Research Clusters were formed, where participation was voluntary, and form and content of the clusters were left at the discretion of participants. One such cluster was the sustainability research cluster. However, even though there was institutional support, and potential faculty were invited to meetings via individualized emails, participation remained low, and the cluster was disowned soon after initial contacts were made with the few faculty who were interested in interdisciplinary research.

\section{Interdisciplinary Research}

There are many definitions of interdisciplinary research, and the term itself have evolved over time and have led to other terms such as multidisciplinary and transdisciplinary. While these terms are close in meaning, there are minute differences that one needs to be aware of.

Of these three terms, multidisciplinary implies a weak link between different fields of study, where team members work in parallel or in series but do not interfere with one another, and different fields of study are not integrated to a great extent. Interdisciplinary research is a step beyond multidisciplinary in terms of integrating traditionally separate fields of study in order to solve problems that cannot be tackled adequately by using the traditional disciplinary framework. Transdisciplinary research is a step beyond interdisciplinary in terms of removing disciplinary barriers, where a new common epistemological basis may even form when members of different fields work together for extended periods (Klein, 1990; Klein, 1996; McNeill, 1999; McNeill and García-Godos, 2005; 
Klein, 2008, Oksen et al., 2009; Borrego and Newswander, 2010). The work described herein would be best described as being interdisciplinary research. However, rather than being a collaborative research effort among peers, it must be noted that described projects involved a faculty of engineering and undergraduate students.

\section{Undergraduate student projects and their development}

Engaging students towards the solution of actual problems and challenges societies or institutions face presents valuable opportunities for hands-on learning. Faculty who actively conduct research in sustainability and include undergraduate students in such efforts not only contribute to professional development of students through service learning, but also to the society by bringing sustainable solutions to problems they tackle.

The goal of the article was to convey experiences in initiating and conducting interdisciplinary undergraduate research on sustainability. Three separate projects are described in this section to present specific examples on how such projects were developed, their interdisciplinary nature, and challenges and rewards of carrying out such research. While brief descriptions of each project were provided, their results are outside the scope of this article and so were not presented in the article. Even though each project was unique in its own way, there were commonalities between them that were presented in the discussions and conclusions section.

The three projects described herein were selected based on their interdisciplinary research potential, and that they were conducted by the author over a similar or overlapping timeframe. The results and discussions that follow were mainly based on reflections and experiences of the faculty involved. Such reflections involved perceptions about student experiences and observed development during the timeframe of the project through project deliverables. Therefore, although a formal standardized procedure to assess student learning was not setup, student progress has been tracked via indirect measures through project deliverables and communications.

\section{Project 1}

A novel interdisciplinary research experience was made possible via a competitive summer undergraduate research fellowship program offered within our institution. Other than being a prestigious achievement for awardees, the 10-week fellowship program included a stipend and summer housing for the student, as well as a small amount of equipment funds that were to be used for research purposes. The goal of the fellowship is for undergraduate students to gain hands-on experience developing and working on a research project in guidance of a faculty mentor. As such, the program requires that students write the fellowship proposals themselves rather than the faculty mentor, as may be expected in a common research grant application.

An undergraduate student interested in conducting sustainability research by using the research fellowship opportunity was unable to find a faculty mentor within their major degree program, and was directed to the Sustainability Studies program coordinator by

other faculty. The student previously had not taken any course from the faculty mentor, nor 
had any coursework directly linked to sustainability. The undergraduate student had a strong cumulative grade point average of 3.67/4.00. The student was also enrolled to the Honors Program, where only a select few are invited to apply to the program every year, and are then required to complete additional assignments (e.g. Honors Thesis) in order to complete the program.

The undergraduate researcher and the faculty mentor were from different backgrounds: the undergraduate student was a dual major student in the departments of Chemistry and Forensic Science, and the faculty mentor was housed under the Mechanical, Civil, and Environmental Engineering Department and had a background that combined civil engineering with sustainability. Unlike a traditional research approach where both the student and the advisor are within the same department, having different backgrounds turned out to be an invaluable asset throughout the project.

Several meetings were initially held to identify potential projects that would interest both parties, and would build on their different backgrounds. The final project topic was mutually agreed to be on the nexus of sustainability and chemistry, where chemistry laboratory courses were analyzed from a life cycle perspective to identify hotspots in environmental and economic impacts and develop strategies to improve the existing state of practice.

The student researcher's existing knowledge on experiments conducted, types of chemicals used in experiments, subtleties of numerous chemical compounds that were analyzed, together with logistical information on how the laboratory courses were managed and operated enabled a more thorough analysis for the research project that may not have been possible with a student not associated with the Chemistry Program and the laboratory courses. Therefore, crossing traditional disciplinary boundaries in favor of a interdisciplinary research project contributed to the success of the project by expanding scope and improving the amount of detail and accuracy of the study.

\section{Project 2}

Facilities Departments of higher education institutions have a vital role in campus sustainability research especially for technical fields, as not only they can provide the necessary data for research, but also provide stipends for undergraduate researchers working on projects that will help improve the campus or its activities. Another benefit of receiving support from Facilities is it may also enable continuation of proposed strategies once the project is finalized as Facilities staff may then continue administering and maintaining project outcomes, compared to depending heavily on a group of students, who are by nature transitional at an institution.

Facilities wanted to validate that a newly commissioned LEED Gold rated green building was meeting its energy and water consumption goals claimed during its certification, which led to the development of a project where an undergraduate researcher was funded. Both parties benefited from the project: the total cost to Facilities was lower compared to funding a consultant; the student on the project gained invaluable hands-on experience on research specific to green buildings that contributed to their professional development. 
The faculty mentor had a background in civil engineering and sustainable design whereas the undergraduate researcher chosen for the project was majoring in Interior Design, with a minor degree in Sustainability Studies. Similar to Project 1, the advisor and the student formed an interdisciplinary team to solve a technical problem that crossed traditional disciplinary boundaries.

The recruited undergraduate student on the project was also an Honors student, and had showed exemplary performance in the Global Solutions for Sustainability course offered by the faculty advisor. The student also had a very strong cumulative grade point average of 3.94/4.00. The student came pre-equipped with knowledge on interior building design and passive design features to reduce environmental impacts. Knowledge on these concepts enabled more creative and effective solutions to be proposed to improve the current state of the building, compared to a purely civil engineering perspective, as would have been the case had the advisor chosen a student from their own discipline.

\section{Project 3}

Project 3 was also funded by university Facilities and involved a solar photovoltaic array to be located on campus, where the project goal was to improve the efficiency of the array by using easily accessible measures, as well as to improve the visibility of the solar array within the campus community and raise awareness towards energy consumption. Different from Projects 1 and 2, Project 3 required good technical skills as well as strong communication skills to present data so as to maximize its visibility and effectiveness.

The undergraduate student who worked on the project was double majoring in Electrical Engineering and Theatre Arts, and had a strong cumulative grade point average of 3.84/4.00. The faculty advisor had previously known the student as the student was assigned as a grader to a sophomore-level engineering course the advisor had taught. After consulting with faculty from Electrical Engineering, reviewing potential students based on their grade point average, and interviewing several candidates, the chosen student was offered to work on the project. As part of the student's electrical engineering coursework, the student had prior knowledge on workings of solar array components and inverters, as well as adequate software skills to take raw output data from the solar array and present in real-time. Although the student was very knowledgeable on the technical principles of solar array components, a big picture perspective to effectively convey the importance or outcomes of the project to the campus community was a shortfall and hence required greater input from the advisor to meet intended project goals. The project would have benefited from the input of another student who had strong communication skills and good knowledge on sustainability issues, but project funds were limited to only support one undergraduate student.

\section{Discussions}

There are research fields within sustainability science where the use of interdisciplinary research is needed and may be most beneficial to find effective solutions. Market trends indicate that future professionals will need to work in an interdisciplinary environment, 
and undergraduate sustainability research is an ideal opportunity to gain such necessary skills.

All three projects involve working with undergraduate students, who do not share the same technical background as the faculty advisor. Results and experiences from the three projects analyzed suggest that faculty interested in sustainability research should not be apprehensive about working with students from other fields, but on the contrary, should embrace the opportunity for a unique interdisciplinary research project where all involved bring a different perspective and a knowledge set to the project. Such an experience also enhances student learning by promoting critical thinking, creativity, and problem solving abilities as the students are exposed to different types of problems and perspectives. Fundamentals of how projects were initiated, challenges faced, and rewards of an interdisciplinary research project involving an engineering faculty researcher and undergraduate students were presented in Table 1.

Table 1 Description of how projects were initiated, background of undergraduate students, and challenges faced and rewards received during each case

\begin{tabular}{|c|c|c|c|}
\hline & Project 1 & Project 2 & Project 3 \\
\hline Project Initiation & $\begin{array}{l}\text { The student decided } \\
\text { to apply for the } \\
\text { fellowship and was } \\
\text { directed by other } \\
\text { faculty to the advisor } \\
\text { due to his } \\
\text { sustainability } \\
\text { research interests }\end{array}$ & $\begin{array}{l}\text { Recruited successful } \\
\text { student who was } \\
\text { enrolled to the } \\
\text { faculty advisor's } \\
\text { course Global } \\
\text { Solutions for } \\
\text { Sustainability. He } \\
\text { had also expressed } \\
\text { interest and showed } \\
\text { prior knowledge in } \\
\text { green buildings } \\
\text { during the course. }\end{array}$ & $\begin{array}{l}\text { The student was } \\
\text { assigned to the faculty } \\
\text { advisor as a grader in } \\
\text { a sophomore-level } \\
\text { engineering course. } \\
\text { After consulting with } \\
\text { faculty from electrical } \\
\text { engineering, and } \\
\text { reviewing students } \\
\text { based on their grade } \\
\text { point average, the } \\
\text { student was offered to } \\
\text { work on the project. }\end{array}$ \\
\hline Student Major & $\begin{array}{l}\text { Double majoring in } \\
\text { Chemistry and } \\
\text { Forensic Science }\end{array}$ & $\begin{array}{l}\text { Majoring in Interior } \\
\text { Design, minor } \\
\text { degree in } \\
\text { Sustainability } \\
\text { Studies }\end{array}$ & $\begin{array}{l}\text { Double majoring in } \\
\text { Electrical Engineering } \\
\text { and Theatre Arts }\end{array}$ \\
\hline Funding & $\begin{array}{l}\text { UNH Summer } \\
\text { Undergraduate } \\
\text { Research Fellowship } \\
\text { Program }\end{array}$ & $\begin{array}{l}\text { Project funded by } \\
\text { University Facilities } \\
\text { Department }\end{array}$ & $\begin{array}{l}\text { Project funded by } \\
\text { University Facilities } \\
\text { Department }\end{array}$ \\
\hline Challenges & $\begin{array}{l}\text { Finding an initial } \\
\text { idea that would } \\
\text { appeal to both } \\
\text { parties and build on }\end{array}$ & $\begin{array}{l}\text { No major challenges } \\
\text { were encountered } \\
\text { during the project. }\end{array}$ & $\begin{array}{l}\text { Although the student } \\
\text { was knowledgeable on } \\
\text { the technical } \\
\text { principles of solar }\end{array}$ \\
\hline
\end{tabular}


their knowledge required an initial investment of time and effort. arrays, a big picture

perspective to effectively convey the importance of the project to the campus community was a shortfall.

\section{Rewards/Benefits to the Project}

Detailed analysis of
chemicals and
materials used in
chemistry labs as
well as lab course
logistics would not
have been possible
with a student from
an outside discipline
who had not taken
courses that were
analyzed.

The student came pre-equipped with knowledge on interior building design and passive design features, which enabled more creative and effective solutions to be proposed within the project, compared to a mono-disciplinary perspective.
Through past courses in electrical engineering, the student had prior knowledge on solar arrays, as well as knowledge on taking raw data from the solar array and presenting it in realtime.

Among the several proposed factors by Ryser et al. (2009) that may affect project outcomes and success, some were found to be more important than others during administering the three projects. Previous experiences with research work in a related topic, and studentfaculty relationship were found to be important contributors to project success. Marzano et al. (2006) also stress the importance of interpersonal relationships in interdisciplinary studies to enhance effective communication and successful outcomes. Results of this study reinforce their findings. On the other hand, proposed factors of gender, language, and ethnicity were not found to play an important role in determining outcomes for the three cases under consideration. Two other factors, namely overall grade point average and intellectual maturity or age of students, were found to play a significant role toward achieving project goals. While these two factors may be expected to affect any type of research, they become critical for interdisciplinary research as each party is expected to bring a different knowledge base to the project.

Had the faculty advisor chosen to work with students who shared a similar technical background, in that case civil engineering, project outcomes would have suffered. The extent of topics and concepts covered in projects 1 and 3 would not have been the same, and so the scope of the project would have suffered as a result. As for project 2, having a student with a different but related background to green buildings brought more creativity into the project as well as to recommendations presented at the end of the project. Limitations described here should not be seen as only applicable to civil engineers, but the same outcome should be expected to result with other disciplines as well. 
Problems faced within the broad umbrella of sustainability are interdisciplinary, and so should the team trying to propose solutions to such problems. The key therefore is to form a strong interdisciplinary team to work on sustainability projects. At the academic research level, this can be achieved by working with students that are outside the discipline of the faculty advisor. Having spent enough semesters to gain a fundamental understanding of their major discipline, successful students even at the undergraduate level may bring a new perspective to the project and open up new opportunities that would not have been possible by adhering to a traditional mono-disciplinary research approach. However, as indicated above, it is vital to recruit successful students for interdisciplinary research projects in order to achieve project outcomes. The three undergraduate students who worked on the described research projects were very strong academically. In reference to their intellectual maturity, one factor that may be taken as an indication of their maturity level is their very strong grade point averages, combined with their on-going double major or minor degree programs which in itself may be taken as an indication to the readiness of interdisciplinary study, and their enrollment to the Honors program, which is a demanding program at our higher education institution. Combined together, not every undergraduate student can manage these different responsibilities while at the same time committing to a research project.

The three projects described in this article involved undergraduate students working on research projects, and gaining hands-on experience while developing and carrying out research, and reporting research results to the campus community either via technical reports, or via oral presentations. Students working on the projects were academically strong students, and research expectations from them were at a level comparable to students seeking a Master's degree at the same institution. All of the students involved indicated that this was their first experience with an actual research study. To that end, these projects have served to provide undergraduate students with valuable research experience that they can benefit in their professional career by improved organization, presentation, communication, and technical writing skills, if not directly beneficial for those students who decide to continue onto graduate degrees and would therefore be required to carry out independent research with minimal guidance. Furthermore, as project outcomes are disseminated to the field via technical journal publications or conferences with guidance of the involved faculty, this step provides an additional important benefit to undergraduate students whether they join the workforce or continue onto graduate degrees after graduation.

Unlike most of their mono-disciplinary courses, participating in an interdisciplinary research project enables undergraduate students to have a big picture perspective on actual problems, problems that they may also encounter professionally soon after graduation. During the research period, students were required to conduct detailed literature reviews on their respective topics. Carrying out literature review on an interdisciplinary topic broadens the knowledge base of students by enabling them to see the interconnectedness of different disciplines, while at the same time exposing them to new methodologies and tool of analysis. Furthermore, students had the opportunity to apply their technical skills to solve sustainability problems. Through the research experience, students gain a deeper understanding of sustainability issues and the life cycle 
impacts and greater implications of their design decisions, while at the same time practicing and developing their technical skills.

\section{Conclusions}

While there have been many efforts to promote sustainability education, the amount of progress made have remained fairly limited due to numerous reasons. One important factor hindering further development is the traditional silo approach that has dominated higher education teaching and research for a long time. Sustainability requires interdisciplinary approaches to problem solution and therefore requires a new set of tools, and a strong interdisciplinary team working on projects. Experiences and reflections with interdisciplinary sustainability research that goes contrary to traditionally set boundaries in engineering are presented in the article based on three research projects.

Results of the three projects analyzed indicate that faculty interested in sustainability research should not be apprehensive about working with students from other fields. If successful, such a framework brings together the opportunity for a unique interdisciplinary research project where all involved bring a different perspective and knowledge set to the project, therefore enhancing the scope and potential impact of the study. However, limitations of the study should be considered before extrapolating and generalizing results to all forms of interdisciplinary research.

In terms of factors that determine project success and outcomes, previous experiences with research work in a related topic, and student-faculty relationship were found to be important contributors, together with overall grade point average and intellectual maturity or age of students. While these factors may be expected to affect all research, they become critical for interdisciplinary research as each party is expected to bring a different knowledge base to the project.

From an institutional standpoint, forming and supporting interdisciplinary research clusters for faculty did not achieve its intended outcome for our specific higher education institution. As cited from literature, good interpersonal communication is vital for interdisciplinary research. Therefore, it is recommended that other institutions planning similar endeavors should focus more on how to promote interaction among involved faculty.

\section{Acknowledgments}

Financial support was received from the University of New Haven Facilities Department to fund undergraduate students who worked on two projects described in this article. Other financial support to fund a student researcher was received through the University of New Haven Summer Undergraduate Research Fellowship Program, and indirectly through the Carrubba family who are the donors supporting the Fellowship Program.

\section{References}

ABET (2014), “Criteria for Accrediting Engineering Programs, 2012-2013”, available at: http://www.abet.org/DisplayTemplates/DocsHandbook.aspx?id=3143, (accessed 17 March 2014). 
Arbuthnott, K. D. (2009), "Education for sustainable development beyond attitude change", International Journal of Sustainability in Higher Education, Vol. 10 No. 2, pp. 152163.

ASCE (2014), "Code of Ethics”, American Society of Civil Engineers, available at: http://www.asce.org/Leadership-and-Management/Ethics/Code-of-Ethics/, (accessed 17 March 2014).

Borrego, M. and Newswander, L. (2010), "Definitions of interdisciplinary research: Toward graduate-level interdisciplinary learning outcomes", The Review of Higher Education, Vol. 34 No. 1, pp. 61-84.

Brundiers, K., Wiek, A. and Redman, C.L. (2010), "Real-world learning opportunities in sustainability: from classroom into the real world", International Journal of Sustainability in Higher Education, Vol. 11 No. 4, pp. 308-24.

Clark, S. G., Rutherford, M. B., Auer, M. R., Cherney, D. N., Wallace, R. L., Mattson, D. J., Clark, D. A., Foote, L., Krogman, N., Wilshusen, P. and Steelman, T. (2011), “College and university environmental programs as a policy problem (Part 1): Integrating knowledge, education, and action for a better world", Environmental Management, Vol. 47 No. 5, pp. 701-715.

Cortese, A. D. (2003), "The critical role of higher education in creating a sustainable future", Planning for Higher Education, Vol. 31 No. 3, pp. 15-22.

de la Harpe, B. and Thomas, I. (2009), "Curriculum Change in Universities: Conditions that Facilitate Education for Sustainable Development", Journal of Education for Sustainable Development, Vol. 3 No. 1, pp. 75-85.

Elton, L. (2003), "Dissemination of Innovations in Higher Education: A Change Theory Approach", Tertiary Education and Management, Vol. 3 No. 3, pp. 199-214.

Hopkins, C. (2012), "Twenty Years of Education for Sustainable Development", Journal of Education for Sustainable Development, Vol. 6 No. 1, pp. 1-4.

Jarvie, M. (2009), "Evaluation of ABET Program Curricula Criteria for the Integration of Sustainability Related Subject Areas", American Society of Engineering Education 2009 Annual Conference \& Exposition, Austin, Texas.

Kates, R.W., Clark, W.C., Corell, R., Hall, J.M., Jaeger, C.C., Lowe, I., McCarthy, J.J., Schellnhuber, H.J., Bolin, B., Dickson, N.M., Faucheux, S., Gallopin, G.C., Grübler, A., Huntley, B., Jäger, J., Jodha, N.S., Kasperson, R.E., Mabogunje, A., Matson, P., Mooney, H., Moore III., B., O’Riordan, T. and Svedin, U. (2001), "Sustainability science”, Science, Vol. 292 No. 5517, pp. 641-2.

Klein, J. T. (1990), “Interdisciplinarity: History, theory, and practice”, Wayne State University Press, Detroit, MI.

Klein, J. T. (1996), “Crossing boundaries: Knowledge, Disciplinarities, and Interdisciplinarities”, University Press of Virginia, Charlottesville, VA.

Klein, J. T. (2008), "Evaluation of Interdisciplinary and Transdisciplinary Research: A literature Review", American Journal of Preventive Medicine, Vol. 35 No. 2S, pp. 
S116-23.

Lozano, R. (2010), "Diffusion of sustainable development in universities' curricula: an empirical example from Cardiff University", Journal of Cleaner Production, Vol. 18 No. 7, pp. 637-44.

Lozano, R., Lozano, F.J., Mulder, K., Huisingh, D. and Waas, T. (2013), "Advancing Higher Education for Sustainable Development: international insights and critical reflections", Journal of Cleaner Production, Vol. 48, pp. 3-9.

Marzano, M., Carss, D. N. and Bell S. (2006), "Working to make interdisciplinarity work: Investing in communication and interpersonal relationships", Journal of Agricultural Economics, Vol. 57 No. 2, pp. 185-97.

McNeill, D. (1999), "On interdisciplinary research: With particular reference to the field of environment and development", Higher Education Quarterly, Vol. 53 No. 4, pp. 31232.

McNeill, D. and García-Godos, J. (2005), "Doing interdisciplinary research on development and the environment: Critical perspectives on sum's experience", Centre for Development and the Environment, University of Oslo, Norway.

NSF (2006), "Investing in America's Future”, National Science Foundation Strategic Plan for 2006-2011, September 2006.

NSF (2014), "Investing in Science, Engineering, and Education for the Nation's Future", National Science Foundation Strategic Plan for 2014-2018, March 2014.

Nučič, M. (2012), "Is sustainability science becoming more interdisciplinary over time?", Acta geographica Slovenica, Vol. 52 No. 1, pp. 216-28.

Oksen, P., Magid, J. and de Neergaard, A. (2009), "Thinking Outside the Box: Interdisciplinary Integration of Teaching and Research on an Environment and Development Study Programme", Interdisciplinary Science Reviews, Vol. 34 No. 4, pp. 309-26.

Rafols, I., Leydesdorff, L., O'Hare, A., Nightingale, P. and Stirling, A. (2012), "How journal rankings can suppress interdisciplinary research: A comparison between innovation studies and business \& management", Research Policy, Vol. 41 No. 7, pp. 1262-82.

Rowe, D. (2007), "Education for a Sustainable Future", Science, Vol. 317 No. 5836, pp. 3234.

Rusinko, C. A. (2010), "Integrating sustainability in higher education: a generic matrix", International Journal of Sustainability in Higher Education, Vol. 11 No. 3, pp. 250-9.

Ryser, L., Halseth, G. and Thien, D. (2009), "Strategies and Intervening Factors Influencing Student Social Interaction and Experiential Learning in an Interdisciplinary Research Team", Research in Higher Education, Vol. 50 No. 3, pp. 248-67.

Stephens, J. C. and Graham, A.C. (2010), "Toward an empirical research agenda for sustainability in higher education: exploring the transition management framework", Journal of Cleaner Production, Vol. 18 No. 7, pp. 611-8. 
Stewart, M. (2010), "Transforming Higher Education: A Practical Plan for Integrating Sustainability Education into the Student Experience", Journal of Sustainability Education, Vol. 1.

Tilbury, D. (2012), "Learning to Connect: Reflections along a Personal Journey of Education and Learning for a Sustainable Future in the Context of Rio + 20", Journal of Education for Sustainable Development, Vol. 6 No. 1, pp. 59-62.

Uiterkamp, A. J. M. S. and Vlek, C. (2007), "Practice and Outcomes of Multidisciplinary Research for Environmental Sustainability", Journal of Social Issues, Vol. 63 No. 1, pp. 175-97.

Vincent, S., Bunn, S. and Sloane, L. (2013a), Interdisciplinary Environmental and Sustainability Education on the Nation's Campuses 2012: Curriculum Design, National Council for Science and the Environment, Washington, DC.

Vincent, S., Bunn, S. and Stevens, S. (2013b), Sustainability Education: Results from the 2012 Census of U.S. four year colleges and universities, National Council for Science and the Environment, Washington, DC.

\begin{abstract}
About the author
Dr. Can B. Aktaş is an Assistant Professor within the Mechanical, Civil, and Environmental Engineering Department at the University of New Haven. A civil engineer by training, his research experience has been on the nexus of civil engineering and sustainability. His current areas of research include sustainable engineering, sustainability education, green design of the built environment, life cycle assessment, and small-scale renewable energy generation.
\end{abstract}

